\title{
Jean-Pierre Cuq, Isabelle Gruca, Cours de didactique $d u$ français langue étrangère et seconde
}

\section{Maria Margherita Mattioda}

\section{(2) OpenEdition}

1 Journals

\section{Edizione digitale}

URL: https://journals.openedition.org/studifrancesi/40032

DOI: 10.4000/studifrancesi.40032

ISSN: 2421-5856

\section{Editore}

Rosenberg \& Sellier

\section{Edizione cartacea}

Data di pubblicazione: 1 décembre 2004

Paginazione: 434-435

ISSN: 0039-2944

\section{Notizia bibliografica digitale}

Maria Margherita Mattioda, «Jean-Pierre Cuq, Isabelle Gruca, Cours de didactique du français langue étrangère et seconde», Studi Francesi [Online], 143 (XLVIII | II) | 2004, online dal 30 novembre 2015, consultato il 19 mai 2021. URL: http://journals.openedition.org/studifrancesi/40032 ; DOI: https:// doi.org/10.4000/studifrancesi.40032

Questo documento è stato generato automaticamente il 19 mai 2021.

\section{(c)}

Studi Francesi è distribuita con Licenza Creative Commons Attribuzione - Non commerciale - Non opere derivate 4.0 Internazionale. 


\title{
Jean-Pierre Cuq, Isabelle Gruca, Cours de didactique du français langue étrangère et seconde
}

\author{
Maria Margherita Mattioda
}

\section{NOTIZIA}

JEAN-PIERRE CUQ, ISABELLE GRUCA, Cours de didactique du français langue étrangère et seconde, Collection FLE, Grenoble, PUG, 2002.

1 La didattica delle lingue straniere costituisce, tuttora, un argomento complesso e di grande attualità, date le costanti sollecitazioni provenienti dalle varie istanze politiche e sociali che ne alimentano il dibattito. In questo quadro decisamente fluido, pare, dunque, ammirevole lo sforzo degli autori del Cours de didactique du français langue étrangère, Jean-Pierre CUQ (Università de Provence) e Isabelle GRUCA (Université de Nice/Sophia Antipolis), - entrambi docenti di Didattica del francese come lingua straniera (FLE) -, di fissarne le strutture fondamentali e di identificarne i cardini attorno ai quali far convergere gli specialisti e gli attori in formazione. Il volume, il cui titolo, in certo qual modo, non risulta estensivo rispetto ad un'indagine che si propone ambiziosa nelle sue premesse e nei suoi sviluppi, si presenta come uno strumento teorico-pratico con funzioni informative -esplicative. Non si tratta, infatti, di un vero e proprio corso, almeno nel senso comunemente attribuito al termine, quanto piuttosto di una sorta di ampio panorama disciplinare, dal quale è possibile attingere informazioni, riferimenti, percorsi metodologici. In effetti, il volume si delinea piuttosto come una summa delle conoscenze raggiunte nel campo della didattica del Français Langue étrangère, nell'arco del ventennio che ha assistito al sorgere e all'affermarsi nella formazione universitaria della filiera FLE. La sintesi non è certamente il solo obiettivo degli autori, i quali mirano fra le righe ad instillare «le goût d'aller chercher l'information de première main, un certain appétit d'autoformation, et surtout un esprit critique», poiché il profilo dell'insegnante si costruisce mediante 
l'armonizzazione di solidi riferimenti disciplinari e di personali convinzioni teoricometodologiche. A tal fine, i vari capitoli che compongono il testo sono corredati da riferimenti bibliografici puntuali per l'approfondimento delle problematiche trattate, senza dimenticare la presenza di una ricca bibliografia generale in appendice. L'architettura del volume risulta alquanto composita, poiché deve illustrare l'albero concettuale della disciplina e riflettere l'eterogeneità degli elementi che la compongono. La scelta degli autori privilegia, quindi, una struttura stratificata, con diversi livelli di lettura, e incentrata su tre assi fondamentali: il campo disciplinare, le metodologie, le tecniche. La prima parte (Le niveau métadidactique) si estende su quattro capitoli che ritracciano il lungo percorso compiuto dalla didattica delle lingue straniere per strutturarsi come disciplina autonoma e che tentano di definire, diacronicamente e sincronicamente, l'estensione del campo di indagine e i rapporti di contiguità con le altre scienze umane. I costanti "ancrages référentiels" cercano di facilitare la descrizione degli strumenti concettuali che appartengono propriamente alla didattica del FLE con particolare attenzione alle condizioni di appropriazione della lingua, quale il binomio insegnamento/apprendimento e la classe con i suoi attori (apprenant, enseignant), secondo una classificazione di situazioni prototipo. Se il livello metadidattico permette la ridefinizione e il riorientamento di alcuni strumenti concettuali, la seconda parte (Le niveau méthodologique), suddivisa in quattro capitoli, si propone di monitorarne le metodologie, i metodi e le nozioni ad essa relativi. Dalla definizione delle competenze fondamentali che l'apprendimento della lingua straniera pone in gioco (comprensione, espressione, produzione sia orali sia scritte), l'attenzione si sposta sui percorsi di apprendimento che si richiamano alla nozione di progressione, alla concezione della valutazione e alla questione della certificazione delle performances. Non mancano accenni a metodologie speciali come il francese Lingua due, l'insegnamento precoce del FLE e il francese per obiettivi specifici (FOS) che vengono collocate a conclusione di un excursus sulle metodologie e sui metodi, graficamente schematizzato in una pratica tavola sinottica relativa ai manuali di insegnamento del francese dagli anni ' 80 al 2000. Gli strumenti disciplinari lasciano, infine, spazio ai dispositivi di intervento didattico che sono espressione di scelte metodologiche concrete. Così, la terza parte (Le niveau technique) offre in tre capitoli la disamina di una serie di pratiche in uso che vanno dalle procedure formali della grammatica, del lessico, della traduzione ad una didattica della parole, supportata da testi letterari e documenti autentici, e alla descrizione di alcune delle principali tecniche della classe di lingua (esercizi e attività), con un accenno agli apporti delle nuove tecnologie educative.

2 Nell'insieme, il volume offre un valido quadro di riferimento per gli studi sulla Didattica del FLE sia per un pubblico di specialisti, studenti e ricercatori nell'ambito del FLE o della didattica delle lingue, sia per insegnanti coinvolti nelle formazione permanente, sia per neofiti che intendono avvicinarsi a questo genere di studi. 